\title{
Sand Morphology Distribution Characteristics of the Southwest Buguli Desert
}

\author{
Xiangling Zhou ${ }^{1, a}$, Wei Zhang ${ }^{2, b}$ and Shengqing Yu ${ }^{3, c^{*}}$ \\ ${ }^{1}$ College of physics and electrical engineering, Kashgar University, Kashgar, Xinjiang 844000, China \\ ${ }^{2}$ College of physics and electrical engineering, Kashgar University, Kashgar, Xinjiang 844000, China \\ ${ }^{3}$ College of physics and electrical engineering, Kashgar University, Kashgar, Xinjiang 844000, China \\ a273143489@qq.com, b316176613@qq.com, 'chouxl-yx@tom.com \\ * the corresponding author Shengqing $\mathrm{Yu}$
}

Keywords: Sand; Morphology characteristics; Wind-sand flow

Abstract. The morphology of the natural sand in the southwest of Buguli desert, Xingjiang, China, has been studied to determine the sand-mass flux of the wind-sand flow, sand particle size distribution and morphology distribution. The results show that, when the average wind speed is $6.7 \mathrm{~m} / \mathrm{s} 2 \mathrm{~m}$ high from the ground, averagely, about $98.1 \%$ of the winds drifting sands have the particle size ranging from $0.05 \mathrm{~mm}$ to $0.15 \mathrm{~mm}$. Under the wind-sand flow state, the main sand shape is given priority to the rounded or subangular shapes, which account for $94.7 \sim 96.1 \%$. With increasing height from 0 to $4 \mathrm{~cm}$, the probability of finding rounded sands is getting smaller, and the size of sand particles with higher probability to be round is also getting smaller: from the range of $0.15 \sim 0.20 \mathrm{~mm}$ to the range of 0.10 to $0.15 \mathrm{~mm}$.

\section{Introduction}

Sand morphological characteristics is an important symbol to determine the degree of wind blowing and also an important identification of the eolian standard[1,2,3]. Research on the characteristics of desert sand in ground wind-sand flow benefits the understanding of physical characteristics of wind-sand flow and, indirectly, the mechanical characteristics of wind-sand flow. At the same time, it provides a reference for the sand bed simulation and experimental study of characteristics of granular materials. It can also provide a clue for understanding the origin of desert sand materials and the formation of sand dunes $[4,5,6,7]$. The research would also help on the prevention and control of desertification.

There are several studies on the natural sand morphology in different deserts $[8,9,10]$ or the sand of the atmosphere. The characteristics of particle size and shape distributions of sand dunes is studied, and sand grains were divided into six kinds, namely well rounded, rounded, subrounded, subangular, angular and cuspidal angular[11]. Uday et al. [12] studies the morphology of the same samples of coarse-grained soil with confocal microscopy, 3-D laser microscopy and laser obscuration time method. By comparing these methods he shows limitations of some methods in the study of particle morphology and suggests a better technique. Zhu [13] uses three indicators -- angular, angular-rounded and rounded shapes of sand particles to represent the psephicity. His study concludes that rounded sand grains are less than 3\%, and the rest are equally shared by the angular-rounded and angular sand grains. Kang and Dai [14] studies the surface structural characteristics of quartz sand collected in Keriya River Basin of the Taklimakan Desert and concludes that sand particle morphology of that desert area is mainly subangular shape, or called angular-round shaped in same other references. There is a lack of the study on the natural sand morphology in Buguli desert at the edge of Yarkant drainage basin. Buguli desert is a passive shifting desert surrounded by the Kashgar River Valley oasis and Yarkand oasis, and there are desert lakes inside, which make Buguli desert unique in wind-sand environmental characteristics. As an average annual rainfall of about $52 \mathrm{~mm}$, Yuepuhu County is obvious in arid regions. Strong winds in spring and summer 
contribute most to the formation of sandstorms, which seriously impact on local agricultural production and living. Research on the sand morphology distribution characteristics of the sand grains from Buguli desert under both static state and wind-sand flow conditions provides a fundamental materials and data for the management and afforestation of Buguli desert wind-sand environment.

In a desert macro-migration process, the sand transport is mainly a process that wind transports and carries sands and abrades on sand dunes. It is a physical process that two substances of wind and sand interact with each other. Wind-sand flow is a type of sand transport phenomena $[3,15]$ or an eolian sand movement in which the static sand flies up with wind from the dune surface into the air.

Under arid climatic conditions, the wind is a fundamental driving force that shapes the sand morphology and also a fundamental power that shapes the desert topography. Under the wind action, sand particles constantly collide each other during saltation movement. Larger particles $(>100 \mu \mathrm{m})$ are rubbed by small ones, and there are many small irregular pits on their surface forming cream surface and particles of different shapes [16,17]. Research on the characteristics of wind-sand flow is an important issue in the wind-sand movement theory, as well as in the engineering practice of the desertification prevention [18].

\section{Experimental apparatus and sample source}

Sand samples for both static state and wind-sand flow state are from the edge of the Buguli desert, China,

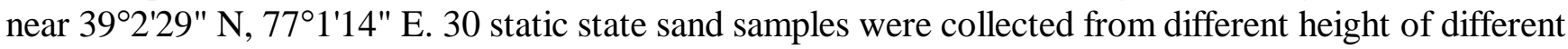
dunes, and sand samples of the wind-sand flow were collected by home-made sand collectors under the wind-sand flow condition.

All sand samples were dried first and, through the sample sieves, divided into six different sizes for each source denoted as samples a (1-2 mm), b (0.5-1 mm), c (0.25-0.5 mm), d (0.125-0.25 mm), e (0.063-0.125 $\mathrm{mm})$ and $\mathrm{f}(0.063 \mathrm{~mm}$ or less). No samples were collected for group a. Each sand sample group was randomly collected three times, and each is consisted of about 200 grains. On the slide, each particle size group of the samples was further divided into a number of roughly equal amount of sand grains, and then observed under an optical microscope (Motic China Group Co., Ltd., Model E221). Their digital images are statistically analyzed to determine their grains morphology distribution. In each size group, the sand particle morphology is classified as angular, sub-angular and rounded shapes by the eyes and the standard graphs are made [8,13]. Fig. 1 is a home-made vertical lattice sand collecting instrument [19].

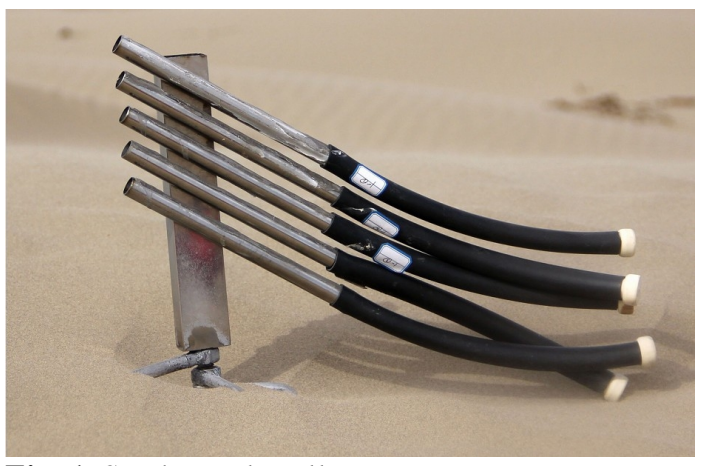

Fig. 1. Sand sample collectors.

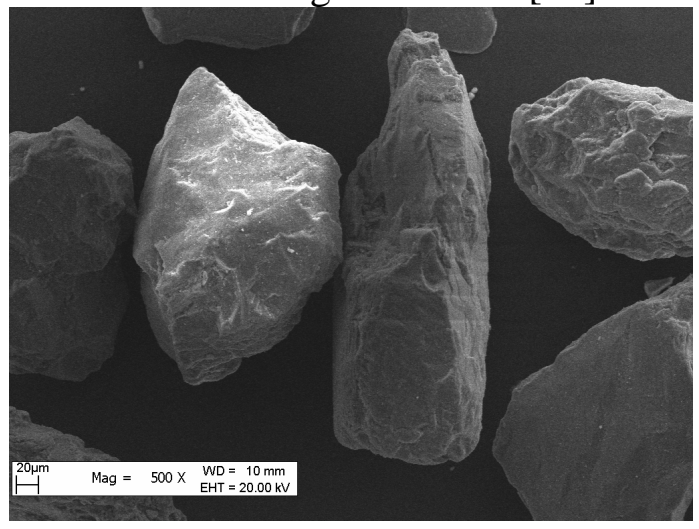

Fig. 2. Photographs of sand grains in sample $b$ under the microscope

The sand collectors were placed in the Buguli desert plains $\left(39^{\circ} 2^{\prime} 29^{\prime \prime} \mathrm{N}, 77^{\circ} 1^{\prime} 14^{\prime \prime} \mathrm{E}\right)$ at different topographic positions of the crescent shape sand dunes, including A (the bottom of windward slope), B (the middle of windward slope), $\mathrm{C}$ (the top of windward slope), and D (the ridge of sand dunes). When there is wind, sands were collected . 


\section{Discussion}

\section{The sand morphology distribution under a static state}

After dividing the sand samples through the sample sieves, the statistics of the ratios of different sand shapes under different particle size is shown in Table 1:

Table 1. The statistical data of the six kinds of particle size of sand shape

\begin{tabular}{cccc}
\hline Sample & $\begin{array}{c}\text { Rounded } \\
\text { shape }\end{array}$ & $\begin{array}{c}\text { Subangular } \\
\text { shape }\end{array}$ & $\begin{array}{c}\text { Angular } \\
\text { shape }\end{array}$ \\
\hline $\mathrm{b}$ & 0 & $34 \%$ & $66 \%$ \\
$\mathrm{c}$ & 0 & $30 \%$ & $70 \%$ \\
$\mathrm{~d}$ & $4 \%$ & $75 \%$ & $21 \%$ \\
$\mathrm{e}$ & $8 \%$ & $81 \%$ & $11 \%$ \\
$\mathrm{f}$ & $4 \%$ & $80 \%$ & $16 \%$ \\
\hline
\end{tabular}

As seen from Table 1, no sands in sample a were collected. In samples b and c, there is no round-shaped sand, and the angular-shaped sand accounts for a largest part, about $66 \% \sim 70 \%$. Subangular shaped sand accounts for $30 \% \sim 34 \%$. Fig. 2 shows magnified images of sand grains in sample b.

As seen in Fig. 2, a few small sand particles are adhered to the large ones. In samples d, e and f, sand particle size is less than $0.25 \mathrm{~mm}$. Round shaped sand grains can be hardly seen, accounting for only $4 \sim$ $8 \%$. So is for sand gains of angular shape, accounting for $11 \sim 21 \%$. However subangular shaped sand accounts for the largest part, about $75 \sim 81 \%$. It is different from the Taklimakan Desert sand morphology distribution mentioned earlier [20]. Both round shaped and angular shaped sands occupy no more than $30 \%$ in these three samples; the round shaped and subangular shaped sands account for the largest portion in the samples.

\section{The sand morphology distribution under wind-sand flow states}

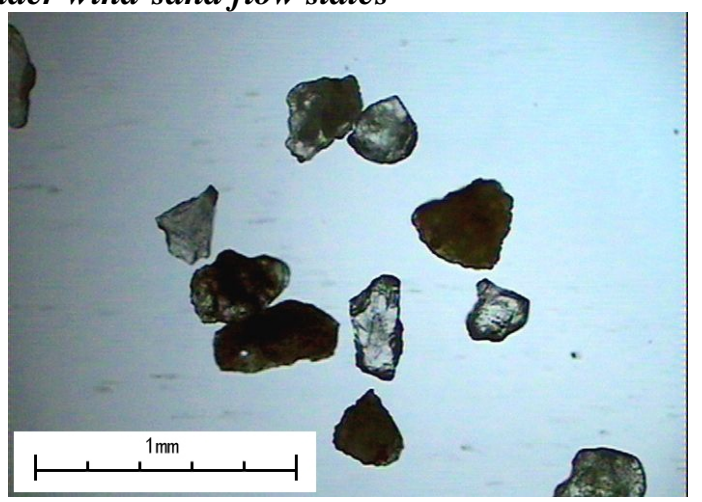

Fig. 3. The sand morphology of particle size within $0.10 \sim 0.15 \mathrm{~mm}$ with a magnification of 40 times.

The statistical random sampling method (Osada et al., 2002) was utilized. The sand morphology photographed under the microscope, and the morphology classification statistical analysis[8,21] were conducted. The classification statistics photographs of the sand morphology of its shape and taking photos. Fig. 3.

Table 2 shows the sand morphology distribution ratio at different topographic positions under wind-sand flow state. At different locations of top and ridge dunes, subangular shaped sands always account for the largest portion, rounded shaped sand, the second, and the angular shaped sand accounts the least portion. This indicates that the topographic location has a little influence on the sand morphology distribution of wind-sand flow.Table 3 shows the sand morphology distribution ratios of different particle size. In the overall distribution of various particle size range, subangular shaped sand always accounts for the largest portion, round shaped sand, the second, and angular shaped sand, the least. In the sand particle size ranges 
Table 2. The sand morphology distribution ratio of different topographic positions

\begin{tabular}{lccc}
\hline & $\begin{array}{c}\text { Rounded } \\
\text { shape }\end{array}$ & $\begin{array}{c}\text { Subangular } \\
\text { shape }\end{array}$ & $\begin{array}{c}\text { Angular } \\
\text { shape }\end{array}$ \\
\hline Top dunes & $25.3 \%$ & $71.1 \%$ & $3.6 \%$ \\
ridge dune & $20.6 \%$ & $74.1 \%$ & $5.3 \%$ \\
\hline
\end{tabular}

Table 3 Sand morphology distribution ratios of different particle size

\begin{tabular}{cccc}
\hline $\begin{array}{c}\text { Particle size } \\
\mathrm{r}(\mathrm{mm})\end{array}$ & $\begin{array}{c}\text { Rounded } \\
\text { shape }\end{array}$ & $\begin{array}{c}\text { Subangular } \\
\text { shape }\end{array}$ & Angular shape \\
\hline $0.05 \sim 0.10$ & $17.3 \%$ & $79.5 \%$ & $3.2 \%$ \\
$0.10 \sim 0.15$ & $37 \%$ & $58.8 \%$ & $4.2 \%$ \\
$0.15 \sim 0.20$ & $36 \%$ & $61.7 \%$ & $2.3 \%$ \\
$0.20 \sim 0.25$ & $20 \%$ & $75.4 \%$ & $4.6 \%$ \\
$0.25 \sim 0.30$ & $5.5 \%$ & $88.9 \%$ & $5.6 \%$ \\
\hline
\end{tabular}

of $0.10 \mathrm{~mm} \sim 0.15 \mathrm{~mm}$ and $0.15 \mathrm{~mm} \sim 0.20 \mathrm{~mm}$, round shaped sand accounts for the largest portion, which indicates that sands in these two size ranges encounter the most serious erosion under wind-sand flow state. Comparing sand morphology distributions under wind-sand flow state and static state (Table 1), we found that, under wind-sand flow state, the ratio of round shaped sand increases, and the ratio of angular shaped sand reduced to less than $10 \%$. It shows that sands of the round shaped and sub-angular shaped, rather than angular shapes, can easily fly up from the dune surface into the air stream.

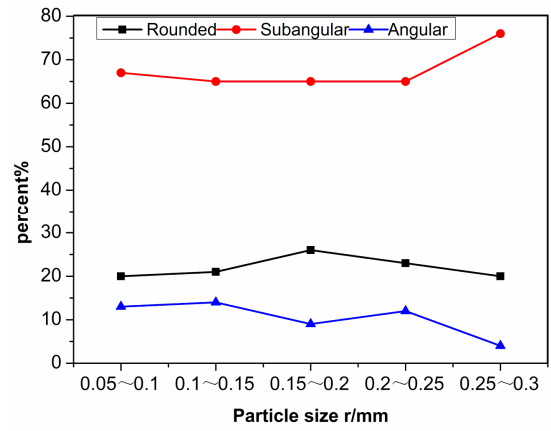

(a)

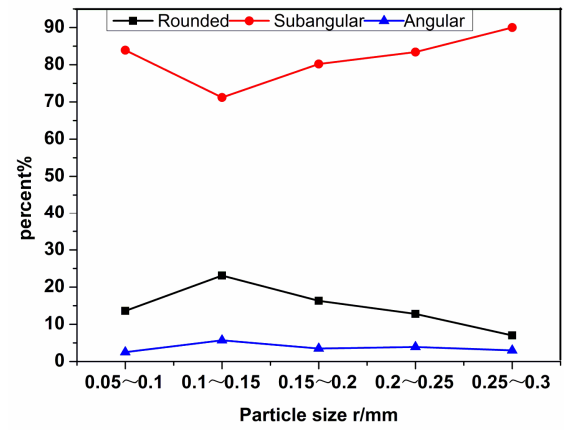

(b)

Fig. 4. The ratio of different sand particle size for different sand particle shapes at the heights of (a) $0 \sim 1.5 \mathrm{~cm}$ and (b) $3 \sim 4.5 \mathrm{~cm}$.

Figs. 4(a) and 4(b) display the sand particle size distribution rations under wind-sand flow state at vertical heights of $0 \sim 1.5 \mathrm{~cm}$ and $3 \sim 4.5 \mathrm{~cm}$, respectively. As seen in Fig. 3, among sand particle size range of $0.15 \sim 0.20 \mathrm{~mm}$, round shaped sand gets the maximum percentage; angular shaped sand always accounts for a small part of all particle size samples under wind-sand flow state. Fig. 4 shows that round shaped sand accounts for the largest part among the sand sample particle size range of $0.10 \sim 0.15 \mathrm{~mm}$; angular shaped sand also accounts for a small portion of each particle size samples under wind-sand flow state. Fig. 4 shows that, at the height of $0 \sim 1.5 \mathrm{~cm}$ under wind-sand flow state, angular shaped sand accounts for approximately $4 \% \sim 14 \%$, the round shaped sand accounts for about $20 \% \sim 26 \%$, and subangular shaped sand accounts for $65 \% \sim 76 \%$. Fig. 4 provides that, at the height of $3 \sim 4.5 \mathrm{~cm}$ from the ground under wind-sand state, the angular shaped sand accounts for about $2.5 \% \sim 5.7 \%$, the portion of round shaped sand is about $7 \% \sim 23 \%$, that of subangular shaped sand is $71.2 \% \sim 90 \%$. It indicates that under wind-sand flow state, the larger the height from the ground, the larger the ratio of subangular shaped sand is, and the smaller the portion of the round shaped and angular shaped sand is. The larger the height from the ground is under wind-sand flow state, the smaller the sand particle size is, and the longer the transporting time is, the more the opportunity of abrasion is.

The probability that the round shaped sand under wind-sand flow state has the size less than $0.10 \mathrm{~mm}$ is small. This fact indicates that the smaller the sand particle size, the less the chance of collision between the sand particles, and so the less the chance of abrasion into the round shaped sand particles. 


\section{Conclusions}

After analyzing the process of eolian sands at the edge of the Buguli desert and the morphology distribution characteristics of natural sand and wind-sand stream, we conclude the following: first, for the eolian sand particle size greater than $0.25 \mathrm{~mm}$ at the edge of the Buguli desert, there is no round shaped sand, the subangular shape sand accounts for a small portion, and the angular shape sand accounts for the largest portion. This is mainly due to the fact that small sand particles would be adhered to large sand particles, and the sand shape becomes larger and angular prominent. Natural sand particle sizes less than $0.25 \mathrm{~mm}$ at the edge of Buguli desert, is mainly subangular shape-based, and accounts for more than $70 \%$. The ratio of the angular shaped sand is less than 20\%, and the round shaped sand accounts for about $10 \%$.

Secondly, the wind speed at the edge of southern Buguli desert ranges from 4.8 to $8.9 \mathrm{~m} / \mathrm{s}$. When the average wind speed is $6.7 \mathrm{~m} / \mathrm{s}$ at $2 \mathrm{~m}$ high from the ground, the wind drifting sand particle size is dominated by particle size ranging $0.05 \sim 0.15 \mathrm{~mm}$, and its ratio is as much as $98.6 \%$. Different topographic positions of sand dunes have different sand-mass flux under wind-sand flow state. Sand-mass flux reaches to its maximum at the ridge and the top of sand dunes, which is the primary location where sands obstacle most. The sand morphology distribution of different topographic positions is similar to each other.

Thirdly, under a wind-sand flow state, sands of larger particle size with subangular and round shapes are easier to encounter the wind erosion than the angular shaped sands, and have a longer transport time in the air and experience more collisions. When the height becomes larger, the particle size of round shaped sand with high distribution ratio becomes smaller.

Fourthly, the sand morphology expresses sand abrasion. The longer the distance over which sands migrate, the more the chance that sands encounter abrasion, the more the sand edges get polished, and the closer the sand grains to become perfect spheres. Round shaped sands account for a small portion under a wind-sand flow state, and this also proves that the Buguli sands are eolian sands with short wind-affecting time and weak wind strength. The major sand shape in the Buguli desert is subangular, while the round shaped sands are only a small fraction in the total sands. This implies that these eolian sands are in their early stage of development. Such sands provide a larger fraction among sand grains and suffer relatively larger resistance, which means, on the other hand, a better chance of the prevention of desertification. Therefore, in the early stage of eolian sands formation, it would be more efficient and lower-cost to prevent from desertification.

\section{Acknowledgement}

This work is supported by the National Natural Science Foundation of China under grant number 11064006, 11564020 and the Department of High Education of the Xinjiang Uygur Autonomous Regions of China under grant number XJEDU2014s056.

\section{References}

[1] Thomas, D.S.G. Analysis of linear dune sediment-form relationships in the Kalahari Dune Desert. Earth Surface Processes and Landforms 13(1988)45 - 553.

[2] Winspear, N.R., Pye, K., 1995. Sand supply to the Algodones dunefield, south-eastern California, USA. Sedimentology 42, 875 - 891.

[3] Lancaster, N., 1995. Geomorphology of Desert Dunes. Routledge, London. pp. 290.

[4] Watson, A., 1986. Grain-size variations on a longitudinal dune and a barchan dune. Sedimentary Geology 46, 49 - 66

[5] Livingstone, I., Bullard, J.E., Wiggs, G.F.S., Thomas, D.S.G., 1999.Grain-size variation on dunes in the Southwest Kalahari, Southern Africa. Journal of Sedimentary Research 69, 546 - 552. 
[6] Krinsley, D.H., Doornkamp, J.C., 1973. Atlas of Quartz Sand Surface Textures. Cambridge University Press, UK. Lancaster, N., 1986. Grain-size characteristics of linear dunes in the southwestern Kalahari. Journal of Sedimentary Petrology 56, 395 - 400.

[7] Zheng Wu, . 1987. Aeolian Geomorphology. Science Press, Beijing. pp.45 - 49, in China.

[8], Zheng Wu., 2003. Geomorphology of wind-drift Sand and their contrlled engineering. Science Press, in China Beijing. pp. 62 - 89.

[9] Gurnell, A.M., Blackall, T. D., Petts, G.E., 2008. Characteristics of freshly deposited sand and finer sediments along an island-braided, gravel-bed river: the roles of water, wind and trees. Geomorphology 99 , $254-269$.

[10] Zhang, H., Nakagawa, H., Mizutani, H., 2012. Bed morphology and grain size characteristics around a spur dyke. International Journal of Sediment Research in China 27, 141 - 157.

[11] Prospero, J., 1999. Long-yange transport of mineral dust in the global atmosphere: Impact of African dust on the environment of the south-eastern Unites States. Proceeding of National Academics Science USA 96, 3396 - 3403.

[12] El-Sayed, M.I., 1999. Sedimentological characteristics and morphology of the aeolian sand dunes in the eastern part of the UAE: a case study from Ar Rub' Al Khali. Sedimentary Geology 123, 219 - 238. [13] Uday, K.V., Padmakumar, G.P., Singh, D.N., 2013. Some studies on morphology of the coarse-grained soils. Engineering Geology 152,48 - 55.

[14] Kang, G.-D., Dai, F.-N., 1988. The Taklimakan Desert Keriya River Basin quartz sand surface structural characteristics. Chinese Desert, 8 (4):46-51.(24) in China.

[15] Tsoar, H., 1986. Two-dimensional analysis of dune profiles and theeffect of grain size on sand dune morphology. In: El-Baz, F., Hassan, M.H.A. (Eds.), Physics of Desertification. Martinus Nijhof, The Hague, pp. 94-108.

[16] Pease, P.P., Bierly, G.D., Tchakerian, V.P., Tindale, N.W., 1999. Mineralogical characterization and transport pathways of dune sand using Landsat TM data. Wahiba Sand Sea, Sultanate of Oman. Geomorphology 29 (3 - 4), 235 - 249.

[17] Abu-Zeid, M.M., Baghdady, A.R., El-Etr, H.A., 2001. Textural attributes, mineralogy and provenance of sand dune fields in the greate $\mathrm{r}$ Al-Ain area, United Arab Emirates. Journal of Arid Environments 48 (4), 475 - 499.

[18] Zheng Wu, The China desert and governance research 50 years. 26(1), 1 - 7. in China

[19] X.L. Zhou,S.Q. Yu, Abdu, M.J, A.G Liu,.2013.The characteristics of blow sands environment in Buguli desert. Arid Land Geography, 35(1)(2009)82 - 90. in China

[20] Z.D Zhu, 1985. Status and trend of desertification in northern China. Journal of Desert Research 5(3), 3 -11. in China.

[21] Padmakumar, G.P., Srinivas, K., Uday, K.V., Iyer, K.R., Pathak, P., Keshava, S.M., Singh, D.N., 2012. Characterization of aeolian sands from Indian desert. Engineering Geology 139 - 140, 38 - 49. 